\title{
Occurrence, sociodemographic, and clinical correlates of eating disorders among a sample of secondary school students in Egypt
}

Walaa Sabry ${ }^{1 *}$ (D, Naglaa EIMahlawy ${ }^{1}$, Heba Essawy ${ }^{1}$, Gamalat Al-Saleet ${ }^{2}$, Mohamed Saad $^{3}$ and Mahmoud Morsy ${ }^{1}$

\begin{abstract}
Background: Eating disorders are common in adolescents. Data on occurrence rates, sociodemographic correlates, and risk factors in Egyptian population are needed along with better screening tools to inform future research and service development. We aimed to estimate the occurrence of eating disorders in a representative sample of Egyptian adolescent students and to examine the sociodemographic and clinical risk factors associated with eating disorders. So, a multistage random selection of 407 adolescent students from public and private secondary schools in Eastern Tanta, Egypt, was carried out. All participants were subjected to screening using the Eating Attitude Test (EAT) and the eating disorders section of the clinician version of the Structured Clinical Interview for DSM-IV axis-I disorders
\end{abstract}

Results: Occurrence estimates of anorexia nervosa and bulimia nervosa were $6.1 \%$ and 3.2\%, respectively. Being female, overweight $\left(B M I=25-29.9 \mathrm{~kg} / \mathrm{m}^{2}\right)$, low self-esteem, and high body shape preoccupation were significantly associated with eating disorders risk among adolescents.

Conclusions: Eating disorders are prevalent in the general adolescent population. The unmet treatment needs in the adolescent population place these disorders as important public health concerns.

Keywords: Eating disorders, Anorexia, Bulimia, Correlates, Egypt

\section{Background}

Adolescence period is a life stage that is highly characterized by body image disturbances due to various physiological, cognitive, emotional, and social changes with a greater concern for physical appearance [1]. Previous studies revealed that adolescents are more susceptible to abnormal eating behaviors and eating disorders [2-5].

Contrary to eating disorders in adults, diagnosis and management of eating disorders is not such an easy issue

\footnotetext{
*Correspondence: Sabrywalaa@yahoo.com

'Okasha's Institute of Psychiatry, The WHO Collaborating Center for Mental Health Research \& Training, Department of Neuropsychiatry, Ain Shams University, Abbasseyia, Ramses Street Extension, Dair Al-Malak, P.O. Box: 11657, Cairo, Egypt

Full list of author information is available at the end of the article
}

in children and adolescents as most of them do not usually meet the full criteria for eating disorder diagnoses [6]. Instead, adolescent age groups usually presented with subthreshold symptoms of eating disorders [7].

Ancient Arab culture regarded fatness as a sign of fertility and femininity for many decades [8]. Other literatures suggested that Egyptian society likes obese females and considers fatness as a symbol of adorableness [9]. These concepts were providing a protective umbrella against eating disorders for a while. However, with the rapid social changes and acculturation occurring in many of the Arab countries, the adolescents' behaviors and attitudes in these countries appear to be changing more towards Western values [10].

\section{Springer Open}

(c) The Author(s). 2020 Open Access This article is licensed under a Creative Commons Attribution 4.0 International License, which permits use, sharing, adaptation, distribution and reproduction in any medium or format, as long as you give appropriate credit to the original author(s) and the source, provide a link to the Creative Commons licence, and indicate if changes were made. The images or other third party material in this article are included in the article's Creative Commons licence, unless indicated otherwise in a credit line to the material. If material is not included in the article's Creative Commons licence and your intended use is not permitted by statutory regulation or exceeds the permitted use, you will need to obtain permission directly from the copyright holder. To view a copy of this licence, visit http://creativecommons.org/licenses/by/4.0/. 
Early identification of eating disorders among school students is crucial, as various studies have confirmed that teachers could be considered as a great aid to the prevention of such disorders, if they receive adequate training [11]. Teachers are hardly receiving training in healthy nutrition styles and eating disorder prevention techniques, so they usually show a great lack of knowledge as a barrier to implement eating disorder prevention programs at schools [12-14].

This motivated the research team to study the magnitude of such an underestimated problem in Egypt. The objectives of this study are to estimate the occurrence of eating disorders in a sample of secondary school students in the Eastern area of Tanta, Egypt, and to examine their associated sociodemographic and clinical risk factors.

\section{Methods}

\section{Study design}

This study is a descriptive, cross-sectional, school-based study.

\section{Site of the study}

This study was conducted in Tanta, Egypt. A sample of adolescent secondary school students in Tanta was drawn. According to statistical data for the academic year 2016/2017, which has been obtained from decisionmaking support and information center, statistical management of Gharbia Governorate, Tanta, is sectioned into Eastern and Western geographical areas; these areas have nearly equal number of students. The Eastern area was included in the study for its easier accessibility to the research team. In Eastern Tanta, both types of schools include totally 12,784 students, and governmental schools include 11,604 students (5955 males and 5649 females) while private schools include $1180 \mathrm{stu}-$ dents (591 males and 589 females).

\section{Calculation of sample size}

The determination of the size of this sample was done after the consultation of a statistician. Stratified random sampling was used in this study sample size and was statistically calculated by considering the total society size $=12,784$, error percentage $=(0.05)$, percentage of availability of the character and objectivity $=70 \%$, and the corresponding standard class of significance $=95 \%$. Thus, the study sample must be not less than 407 according to the used equation of calculated sample size and it was allocated to ensure the suitability of the chosen sample to the total number of students: $300 \mathrm{stu}-$ dents from governmental secondary schools and 107 students from private secondary schools.

From each type of the above-mentioned schools, stratification was done, where two schools were selected by random sampling, then from each selected school, classes were selected also by random sampling, and from the selected class, students were also selected by simple random sampling. The study included students of both genders with an age range between 16 and 18 years and who were agreed to participate in the study. Students with a known history of psychiatric and/or medical disorders or a history of being maintained on any medications were excluded from the study.

\section{Ethical consideration}

The authors received the approval of the Ministry of Education before conducting the study procedures. In addition, a written informed consent was obtained from the school manager for all included students who approved to participate in the study. All subjects were informed about the questionnaires being used in the study and students who only agreed to share in the study were included. Interviews with the students were done at each school in private rooms that were determined by the school manager in order to ensure confidentiality. The study was conducted in accordance with the guidelines of the Research and Ethics Committee of the Institute of Psychiatry, Ain Shams University.

\section{Procedure}

The data were collected by direct interviewing of the students in suitable settings inside their schools during the academic year of 2016-2017. The students completed the following tools:

1- Semi-structured clinical data sheet: Semi-structured clinical data sheet is routinely used at Ain Shams University Institute of Psychiatry. It consists of sociodemographic data, including age, gender, education, and social status.

2- Eating Attitudes Test (EAT40): The Eating Attitude Test (EAT) is the most widely used self-report test for screening large populations for attitudes and symptoms characteristic of eating disorders [15]. The recommended cut-off score is 30 and scores above or equal to 30 are frequently associated with abnormal eating attitudes and behavior [16]. An Arabic translated and validated version was used in this study [17]. The psychometric features of the Eating Attitude Test Questionnaire (EAT) are described in an Egyptian population of secondary school girls $(n=351)$ and pointed to the overall coherence of the EAT in this population [17].

3- Arabic version of Eating disorder section of Structured Clinical Interview for DSM-IV (SCID I Clinical version) [18]: It was used to confirm the diagnosis of axis-I psychiatric conditions and to detect various types of eating disorders. It was chosen 
for relatively easier administration in a clinical setting. The Arabic translated and validated version of the Structured Clinical Interview for DSM-IV axis I Disorders (SCID-I) was used [18]. It was applied on candidates who were found positive on EAT-40 Scale (with EAT40 score $\geq 30$ ).

4- Body Shape Questionnaire-Revised-10 (BSQ-R-10)

[19] Arabic version [20]: The Body Shape Questionnaire (BSQ) is a widely used scale to assess body dissatisfaction. It has been found to be valid by Cooper and colleagues (1987) [21]. Its concurrent validity was established by the significant correlations between BSQ-34 (the original version) and the total score of EAT26 and Body Dissatisfaction subscale of Eating Disorder Inventory Questionnaire. It was administered to assess the degree to which one is preoccupied with the size and shape of one's body. Several short forms of the BSQ have been introduced. One of them is the BSQ-R-10, on which items are scored on a 6-point Likert scale, ranging from 1 , never, to 6 , always. The total scores range from 1 to 6 , and higher scores indicate increased preoccupation with body shape [19]. the BSQ-R-10 was cross-validated in another sample of female adolescent students, and its psychometric properties were further supported. The Arabic translated and version was used in this study [20].

5- Self-esteem Scale [22]: The self-esteem scale is an Arabic self-reported questionnaire that was designed to measure the overall self-esteem of the reporter. It assesses the self-view of the reporter to his capabilities in different situations. It is composed of 30 items rated as follows: frequently $=2$, sometimes $=1$, and never $=0$. Items indicating low selfesteem are inversely scored. Higher scores indicate higher self-esteem, and it was validated and standardized to be used in various age groups including adolescents [22]. Sociodemographic data were reported, and height and weight were measured for all students who agreed to participate in the study. Then, EAT40, BSQ-R-10, and Self-esteem Scale were administered for all students who agreed to participate in the study. Lastly, SCID-I was applied only for the students with EAT40 score $\geq 30$ in private places that were determined by their school managers.

\section{Statistical analysis}

The collected data were statistically analyzed using SPSS software (Statistical Package for the Social Sciences, version 19, SPSS Inc. Chicago, IL, USA). For quantitative data, the range, mean, and standard deviation were calculated. Boxplots were performed to illustrate median and first and third quartiles of the quantitative data.

For qualitative data, which describes a categorical set of data by frequency, percentage, or proportion of each category, comparison between two groups and more was done using chi-square test $\left(\chi^{2}\right)$ and Fisher's exact test.

For comparison between means of two groups of parametric data of independent samples, Student's $t$ test was used.

To predict the presence or absence of an outcome based on a set of predictor variables, binary logistic regression and multinomial logistic regression were done. For each of the independent variables, logistic regression coefficients (B) are calculated and used to estimate odds ratios (EXP (B)) for each of the independent variables as risk factors for eating disorders and its types among the studied secondary school students.

$P$ value was considered significant when $P<0.05^{*}$ and highly significant when $P<0.001^{* \%}$.

\section{Results}

\section{Sample characteristics}

The study sample included 407 secondary school students: 207 were males (50.9\%) and 200 were females (49.1\%). The mean age for the studied sample was 16.05 \pm 0.23 years, and they were distributed as 107 students (26.3\%) from private schools and 300 students (73.7\%) from governmental schools. Their body weight ranged between 34 and $130 \mathrm{~kg}$ with a mean of $65.06 \mathrm{~kg} \pm 14.84$ (other sociodemographic and clinical data are shown in Table 1).

Results revealed that 83 students $(20.4 \%$ of the study sample) were highly preoccupied with their body shape using the body shape questionnaire-revised-10 (BSQ-R10 ) and that 14 students (3.4\% of the study sample) were having a low level of self-esteem using the Self-esteem Scale.

The Eating Attitude Test scores among the studied sample ranged between 3 and 61 with a mean of $18.53 \pm$ 9.25. A percentage of $9.3 \%$ of the studied population were estimated to meet criteria for eating disorders according to the eating attitudes test (EAT) cut-off point.

\section{Occurrence of eating disorders (diagnosed by SCID-1) and} its types among the study sample $(n=407)$

By the use of SCID-I, it confirmed that $9.3 \%$ of the studied population have been diagnosed with eating disorders, distributed as 13 students $(3.2 \%$ of the total sample) were having anorexia nervosa and 25 students (6.1\% of the total sample) were suffering from bulimia nervosa (Table 2). 
Table 1 Sociodemographic and clinical characteristics of the study sample

\begin{tabular}{|c|c|c|}
\hline \multirow[t]{2}{*}{ Variables } & \multicolumn{2}{|c|}{$\begin{array}{l}\text { Secondary school students } \\
(n=407)\end{array}$} \\
\hline & Range & Mean \pm SD \\
\hline Age, year & $16-17.5$ & $16.05 \pm 0.23$ \\
\hline Father's income & $N$ & $\%$ \\
\hline No income & 1 & 0.2 \\
\hline Not enough & 23 & 5.7 \\
\hline Enough & 227 & 55.8 \\
\hline Enough and spare & 156 & 38.3 \\
\hline Father's description & $N$ & $\%$ \\
\hline Kind & 338 & 83 \\
\hline Dominant & 58 & 14.3 \\
\hline Harmful & 6 & 1.5 \\
\hline Dictatorial & 5 & 1.2 \\
\hline Mother's description & $N$ & $\%$ \\
\hline Kind & 364 & 89.4 \\
\hline Dominant & 34 & 8.4 \\
\hline Harmful & 4 & 1 \\
\hline Dictatorial & 51 & 1.2 \\
\hline Crowding index & $N$ & $\%$ \\
\hline One & 54 & 13.3 \\
\hline Two & 329 & 80.8 \\
\hline Three & 24 & 5.9 \\
\hline Home atmosphere & $N$ & $\%$ \\
\hline Warm & 202 & 49.6 \\
\hline Peaceful & 51 & 12.5 \\
\hline Over-criticizing & 37 & 9.1 \\
\hline Full of problems, annoying & 117 & 28.7 \\
\hline Body weight & $34-130$ & $65.06 \pm 14.84$ \\
\hline Body mass index (BMI) & $16-45$ & $23.72 \pm 4.72$ \\
\hline Eating attitudes test scores & $3-61$ & $18.53 \pm 9.25$ \\
\hline Body shape preoccupation & No & $\%$ \\
\hline $\begin{array}{l}\text { High preoccupation ( } \geq 40 \text { scores) } \\
\text { (40-60) }\end{array}$ & 83 & 20.4 \\
\hline $\begin{array}{l}\text { Low preoccupation (< } 40 \text { scores) } \\
(10-39)\end{array}$ & 324 & 79.6 \\
\hline Body shape preoccupation & No & $\%$ \\
\hline $\begin{array}{l}\text { High preoccupation ( } \geq 40 \text { scores) } \\
(40-60)\end{array}$ & 83 & 20.4 \\
\hline $\begin{array}{l}\text { Low preoccupation (< } 40 \text { scores) } \\
(10-39)\end{array}$ & 324 & 79.6 \\
\hline Body shape preoccupation & No & $\%$ \\
\hline $\begin{array}{l}\text { High preoccupation ( } \geq 40 \text { scores) } \\
(40-60)\end{array}$ & 83 & 20.4 \\
\hline Low preoccupation (< 40 scores) & 324 & 79.6 \\
\hline
\end{tabular}

Table 1 Sociodemographic and clinical characteristics of the study sample (Continued)

\begin{tabular}{lll}
\hline Variables & \multicolumn{2}{l}{$\begin{array}{l}\text { Secondary school students } \\
(\boldsymbol{n}=\mathbf{4 0 7})\end{array}$} \\
\cline { 2 - 3 } & Range & Mean \pm SD \\
\hline $\begin{array}{l}\text { Body Shape Questionnaire-Revised-10 } \\
\text { (BSQ-R-10) total scores }\end{array}$ & Range & Mean \pm SD \\
Self-esteem levels & $10-60$ & $28.6 \pm 13.07$ \\
Low level (< 40\%) (0-23) & No & $\%$ \\
$\quad \begin{array}{l}\text { Moderate and high levels } \\
\text { (40-100\%) (24-60) }\end{array}$ & 14 & 3.4 \\
Self-esteem scale scores & 393 & 96.6 \\
& & \\
& Range & Mean \pm SD \\
& $11-58$ & $39.65 \pm 8.99$ \\
\hline
\end{tabular}

Comparison between students with and without eating disorders $(n=407)$

Results showed that eating disorders are highly prevalent among female students $(P$ value $=0.0001)$, as eating disorders were prevalent in only 7 male students in comparison to 31 female students, while other sociodemographic factors were not found to be significantly different among students with and without eating disorders (as shown in Table 3).

Results revealed that there was a significant statistical difference between students with and without eating disorders with regards to their body mass index, body shape preoccupation, low self-esteem $(P$ value $\leq 0.008$, $0.000,0.000$, respectively) (detailed data are illustrated in Table 4). The mean body weight among students with bulimia nervosa $(75.12 \mathrm{~kg} \pm 18.52)$ was significantly higher than that students with anorexia nervosa (55.46 $\mathrm{kg} \pm 8.92)$. Similarly, students with bulimia nervosa were having a significantly higher body mass index $(27.99 \mathrm{~kg} /$ $\left.\mathrm{m}^{2} \pm 6.14\right)$ than students with anorexia nervosa $(21.13$ $\left.\mathrm{kg} / \mathrm{m}^{2} \pm 2.48\right)$.

\section{Predictive factors of eating disorders among the study sample.}

Logistic regression analysis was used to detect the predictive factors of eating disorders. We found that female gender, overweight $\left(\right.$ BMI $\left.=25-29.9 \mathrm{~kg} / \mathrm{m}^{2}\right)$, low selfesteem, and high body shape preoccupation are predictive factors for eating disorders among adolescent students (as shown in Table 5).

\section{Discussion}

Adolescence period is frequently accompanied with special types of problems including body dissatisfaction and disturbed eating behaviors. Adolescent eating disorders are usually having a chronic course and associated with serious psychiatric and medical co-morbidities and complications [23]. 
Table 2 Prevalence and types of eating disorders among the study sample

\begin{tabular}{lll}
\hline Variables & \multicolumn{2}{l}{$\begin{array}{l}\text { Secondary school students in } \\
\text { Eastern Tanta }(\boldsymbol{n}=\mathbf{4 0 7})\end{array}$} \\
\cline { 2 - 3 } & $\boldsymbol{N}$ & \% \\
\hline Students with eating disorders & 38 & 9.3 \\
$\begin{array}{l}\text { Students without eating disorders } \\
\text { Types of eating disorders: }\end{array}$ & 369 & 90.7 \\
Anorexia nervosa & 13 & \\
Bulimia nervosa & 25 & 3.2 \\
\hline
\end{tabular}

In the current study, the prevalence of eating disorders (EDs) in a representative scholastic sample was evaluated, and demographic and clinical factors associated with ED were assessed.

The results showed that male participants were significantly $(P \leq 0.0001)$ heavier and taller than their female counterparts. These data are concordant with the general view that males were significantly heavier than females from various studies all over the world [24, 25].

The difference between males and females with regards to body weight could be explained with many biological factors like lower total muscle mass in females than males [26]; males convert more of their caloric intake into muscle, while females tend to convert more into fat deposits [27]. In addition, the greater muscular mass in males is described to be due to muscular hypertrophy as a result of higher levels of circulating testosterone in their blood [28].

Unsurprisingly, the current study showed that female students are significantly more preoccupied with their body shape (BSQ-R-10 $=31.68 \pm 13.81$ ) than their male counterparts (BSQ-R-10 $=25.63 \pm 11.60$ ). These data are in agreement with the results of previous studies which indicated that adolescent females significantly put greater importance of both body weight and shape on self-evaluation than males [29-32].

On the Eating Attitude Test (EAT), we found that 9.3 $\%$ of Egyptian adolescents had a tendency for disturbed eating behavior. Mintz and O'Halloran (2000) [33] reported a high specificity rate for the EAT-40 with an accuracy rate of at least $90 \%$ when used to differentially diagnose those with and without eating disorders. It also has an accepted discriminant capacity between clinical and non-clinical samples. This was replicated in the current study, which revealed that all (EAT-40) positive scorers were proved to have a full threshold eating disorder by SCID-1 interview.

These results are consistent with those of other Egyptian studies [17, 34, 35]. Moreover, our results also agreed with the results of many other studies in Arab and Western countries [36-38].
However, the results of a study investigating the eating disturbances among adolescent school girls in Jordan reported that eating disorder occurrence in a population sample using DSM-IV-TR diagnostic criteria is $33.4 \%$ which is higher than that observed in both Western and non-Western world [39]. Other studies reported much lower prevalence rates of eating disorders in adolescence. For example, Swanson and his colleagues found that eating disorders are prevalent in 3\% of their adolescent samples [40]. These differences between various studies may be due to the variabilities in sample size, study setting and design, and the studies' targeted age and gender groups.

Moreover, the current study showed that bulimia nervosa is the commonest type of eating disorder encountered in the study sample $(6.1 \%$ (25) students), while $3.2 \%$ (13 students) were having anorexia nervosa.

Although, the most common diagnosis of eating disorders among adolescents is Eating Disorder Not Otherwise Specified (EDNOS), the current study did not find any students with that diagnosis. The reason behind that may be due to the specific psychometric properties of EAT-40 with its ability to differentiate between threshold, subthreshold, and undifferentiated forms of eating disorders, with an accuracy rate of at least $90 \%$. These results were found during the EAT-40 validation with DSM-IV eating disorder criteria [33]. It is consistent with the findings of this current study that all students with abnormal eating attitudes and behaviors (with EAT-40 score $\geq 30$ ) have an eating disorder which was further confirmed by SCID-I.

Contrary to our study, other previous studies revealed lower prevalence rates for anorexia nervosa among adolescents. Prevalence of anorexia nervosa varied from 0 to $1.7 \%$ in previous American and European studies [41-45].

For a long time, anorexia and bulimia have been classified as a Western disorder or the disorder of the developed world, but the current study results clearly demonstrated that this assumption might not be true and confirmed the results of some other studies, which reported that the level of eating disorders is rising in the developing countries [46].

The higher estimate of AN in our study may reflect the highest level of underestimation of such disorders among this age group. This could reveal the huge magnitude of such mental health problems with decreased awareness of these disorders and limited access to health care specialists and appropriate interdisciplinary teams.

On the other hand, the prevalence of bulimia nervosa differs widely across different studies, with estimates ranging from 0.9 to $4.6 \%$ [44, 47, 48]. In a previous Egyptian study, bulimia nervosa was prevalent among 14 adolescent secondary school students (6.8\%) from a total 
Table 3 Comparison between students with and without eating disorders as regards sociodemographic data

\begin{tabular}{|c|c|c|c|c|c|}
\hline \multirow{3}{*}{$\begin{array}{l}\text { Variables } \\
\text { Age (years) }\end{array}$} & \multicolumn{4}{|c|}{ Secondary school students in Eastern Tanta } & \multirow{3}{*}{$\begin{array}{l}X^{2} \text { or } t \text { test } \\
\text { and } P \\
\text { value } \\
t=0.04\end{array}$} \\
\hline & \multicolumn{2}{|c|}{ With eating disorders $(n=38)$} & \multicolumn{2}{|c|}{ Without eating disorders $(n=369)$} & \\
\hline & Range & Mean \pm SD & Range & Mean \pm SD & \\
\hline & $16-17$ & $16.05 \pm 0.23$ & $16-17.5$ & $16.05 \pm 0.23$ & $P=0.968$ \\
\hline Gender & $N$ & $\%$ & $\mathbf{N}$ & $\%$ & $X^{2}=17.647$ \\
\hline Males & 7 & 18 & 200 & 54 & $P=0.0001^{* *}$ \\
\hline Females & 31 & 82 & 169 & 46 & \\
\hline Father's income & $N$ & $\%$ & $N$ & $\%$ & $x^{2}=3.854$ \\
\hline No income & 0 & 0 & 1 & 0.3 & $P=0.2 / 8$ \\
\hline Not enough & 4 & 10.5 & 19 & 5.1 & \\
\hline Enough & 24 & 63.2 & 203 & 55 & \\
\hline Enough and spare & 10 & 26.3 & 146 & 39.6 & \\
\hline Father's description & $N$ & $\%$ & $N$ & $\%$ & $x^{2}=3.979$ \\
\hline Kind & 29 & 76.3 & 309 & 83.7 & $P=0.264$ \\
\hline Dominant & 9 & 23.7 & 49 & 13.3 & \\
\hline Harmful & 0 & 0 & 6 & 1.6 & \\
\hline Dictatorial & 0 & 0 & 5 & 1.4 & \\
\hline Mother's description & $N$ & $\%$ & $N$ & $\%$ & $X^{2}=2.31$ \\
\hline Kind & 34 & 89.5 & 330 & 89.4 & $P=0.511$ \\
\hline Dominant & 2 & 5.3 & 32 & 8.6 & \\
\hline Harmful & 1 & 2.6 & 3 & 1 & \\
\hline Dictatorial & 1 & 2.6 & 4 & 1 & \\
\hline Crowding index & $N$ & $\%$ & $N$ & $\%$ & $x^{2}=0.032$ \\
\hline One & 5 & 13.2 & 49 & 13.3 & \\
\hline Two & 31 & 81.5 & 298 & 80.7 & \\
\hline Three & 2 & 5.3 & 22 & 6 & \\
\hline Home atmosphere & $N$ & $\%$ & $N$ & $\%$ & $X^{2}=5.434$ \\
\hline Warm & 8 & 21.1 & 109 & 30 & \\
\hline Peaceful & 17 & 44.7 & 185 & 50 & \\
\hline Over-criticizing & 6 & 15.8 & 45 & 12 & \\
\hline Full of problems, annoying & 7 & 18.4 & 30 & 8 & \\
\hline
\end{tabular}

$X^{2}=$ chi-square test, $P$ value: $\left({ }^{*}\right)$ significant if $P<0.05$ and $(* *)$ highly significant if $P<0.001$

$t=$ Student's $t$ test

of 205 students [35] which is consistent with the finding of the current study (6.1\%).

Assessment of sociodemographic factors associated with eating disorders among Egyptian adolescents revealed that they are notably prevalent in females than males ( $82 \%$ of them were females and $18 \%$ were males), which is consistent with other various studies $[49,50]$. Girls are more likely than boys to have weight and body dissatisfaction, body image concern, and dieting for weight control [30, 32].

Adolescence obesity/overweight and weight fluctuations may be considered as a risk factor for eating disorders later on in adulthood. Overweight girls showed some of the psychological features associated with the development of EDs, including a link between concerns and self-esteem based on physical appearance [51]. Our study showed a higher mean body weight and body mass index among students with eating disorders than those without eating disorders. Further longitudinal follow-up studies are needed to demonstrate the relation between childhood body weight, BMI, and later development of eating disorders in adolescence.

Body shape and self-esteem play an important role in the development of eating disorders in adolescence [52]. Our data are highly concordant with this finding, as 68.4\% of Egyptian students with eating disorders are highly preoccupied with their body shape in comparison to those without eating disorders (15.4\%) with a highly 
Table 4 Comparison between students with and without eating disorders as regards clinical characteristics

\begin{tabular}{|c|c|c|c|c|c|}
\hline \multirow[t]{3}{*}{ Variables } & \multicolumn{4}{|c|}{ Secondary school students in Eastern Tanta } & \multirow{3}{*}{$\begin{array}{l}t \text { test } \\
P\end{array}$} \\
\hline & \multicolumn{2}{|c|}{ With eating disorders $(n=38)$} & \multicolumn{2}{|c|}{ Without eating disorders $(n=369)$} & \\
\hline & Range & Mean \pm SD & Range & Mean \pm SD & \\
\hline Body weight (kg) & $40-130$ & $68.39 \pm 18.38$ & $34-120$ & $64.72 \pm 14.42$ & $\begin{array}{l}1.455 \\
0.147\end{array}$ \\
\hline Body mass index (BMI) & $17-45$ & $25.65 \pm 6.11$ & 16-39.6 & $23.52 \pm 4.52$ & $\begin{array}{l}2.663 \\
0.008^{*}\end{array}$ \\
\hline EAT-40 score & $30-61$ & $38.08 \pm 8.4$ & $3-29$ & $16.51 \pm 6.62$ & $\begin{array}{l}18.61 \\
0.0001^{* *}\end{array}$ \\
\hline Body shape preoccupation & $N$ & $\%$ & $N$ & $\%$ & \\
\hline High (40-60 scores) & 26 & 68.4 & 57 & 15.4 & $X^{2}=59.553$ \\
\hline \multirow[t]{2}{*}{ Low (10-39 scores) } & 12 & 31.6 & 312 & 84.6 & $P=0.0001^{* *}$ \\
\hline & Range (10-60) & Mean \pm SD & Range & Mean \pm SD & \\
\hline BSQ-R-10 total score & $32-60$ & $47.31 \pm 9.66$ & $10-60$ & $26.68 \pm 11.80$ & $\begin{array}{l}t=10.423 \\
P=0.0001^{* *}\end{array}$ \\
\hline Self-esteem & $N$ & $\%$ & $N$ & $\%$ & \\
\hline Low (0-23 score) & 9 & 23.7 & 5 & 1.4 & $x^{2}=51.717$ \\
\hline \multirow[t]{2}{*}{ Moderate \& High (24-60 score) } & 29 & 76.3 & 364 & 98.6 & $P=0.0001^{* *}$ \\
\hline & Range $(0-60)$ & Mean \pm SD & Range & Mean \pm SD & \\
\hline Self-esteem score & $11-42$ & $25.92 \pm 5.97$ & $16-58$ & $41.06 \pm 8$ & $\begin{array}{l}t=11.333 \\
P=0.0001^{* *}\end{array}$ \\
\hline
\end{tabular}

significant statistical difference between them. In addition, students with eating disorders a have highly significant lower self-esteem (mean self-esteem score $=$ $25.92 \pm 5.97)$ than students without eating disorders (mean self-esteem score $=41.06 \pm 8.00$ ).

In agreement with other studies [38, 53, 54], our study showed that female gender, overweight (BMI $=25-29.9$ $\mathrm{kg} / \mathrm{m}^{2}$ ), low self-esteem, and high body shape preoccupation are significant predictive factors for the occurrence of eating disorders among adolescents.

One significant strength of our study was derived from using a representative sample, having high initial participation rates and low attrition rates, which closely represented the broader adolescent population.

Various limitations should also be considered in interpreting our results. First, being a cross-sectional design did not allow us to get causal inferences. Further longitudinal studies are required to confirm the causeeffect relationships. Second, the use of (EAT) may limit the detection of students with subthreshold symptoms of eating disorders.

\section{Conclusions}

The finding of this study revealed that adolescent eating disorders are a highly prevalent but underestimated mental health problem in Egypt. Nonetheless, our findings might shed light on multiple sociodemographic and clinical correlates for adolescent eating disorders. This involves a complex interplay of biological, social, cultural, and psychological factors. More research is needed to explore the mechanisms behind it. Provision of a simple screening tool for eating disorders at schools and educational institutions is highly recommended.

Table 5 Predictive factors of eating disorders among the study sample

\begin{tabular}{|c|c|c|c|c|c|c|}
\hline \multirow[t]{2}{*}{ Independent variables } & \multirow[t]{2}{*}{ B } & \multirow[t]{2}{*}{ SE } & \multirow{2}{*}{$\begin{array}{l}\text { EX } \\
\text { (B) }\end{array}$} & \multicolumn{2}{|c|}{ Confidence interval (CI) } & \multirow{2}{*}{$\begin{array}{l}\text { Sig. ( } P \\
\text { value) }\end{array}$} \\
\hline & & & & Lower limit & Upper limit & \\
\hline \multicolumn{7}{|l|}{ Predictive factors } \\
\hline Female gender & 1.957 & 0.492 & 7.077 & 2.698 & 18.559 & $0.0001^{* *}$ \\
\hline Overweight (BMI = 25-29.9) & 1.482 & 0.718 & 4.401 & 1.078 & 17.976 & $0.039^{*}$ \\
\hline Low self-esteem level (0-23 score) & 1.430 & 1.562 & 0.239 & 0.011 & 5.113 & $0.0001^{* *}$ \\
\hline High body shape preoccupation (40-60 score) & 2.079 & 0.445 & 0.125 & 0.052 & 0.299 & $0.0001^{* *}$ \\
\hline
\end{tabular}

$P$ value: $\left.{ }^{*}\right)$ significant if $P<0.05$ and $\left(^{* *}\right)$ highly significant if $P<0.001$

$B$ logistic regression coefficient, $S E$ standard error of $B, \operatorname{Exp}(B)$ estimated odds ratio 


\section{Abbreviations}

AN: Anorexia nervosa; B: Logistic regression coefficient; BMl: Body mass index; BSQ-R-10: Body Shape Questionnaire-Revised-10; Cl: Confidence interval; EAT: Eating Attitude Test; ED: Eating disorders; EDNOS: Eating Disorder Not Otherwise Specified; Exp (B): Estimated odds ratio; SCIDI: Structured Clinical Interview for DSM-IV axis I Disorders; SE: Standard error of $\mathrm{B}$

\section{Acknowledgements}

We would like to thank all participants who dedicated their time and attention to participate in this work.

\section{Authors' contributions}

WS designed the methodology. GS analyzed and interpreted the patient data. NM was the founder of the research idea. HE reviewed the methodology and results. MS collected the patient data. MM and WS were major contributors in writing the manuscript. All authors read and approved the final manuscript

\section{Funding}

The authors of this manuscript declare that no funding bodies were involved in sponsoring or funding this research.

\section{Availability of data and materials}

All data generated or analyzed during this study are included in this published article.

\section{Ethics approval and consent to participate}

The authors received the acceptance of the Ministry of Education before starting the study procedures. In addition, a written informed consent was obtained from the school manager for all included subjects who agreed to participate in the study. All subjects were informed about the questionnaires being used in the study and students who only accepted to share in the study were included. Interviews with the students were done at each school in private places that were determined by the school manager. The study was conducted in accordance with the guidelines of the Research and Ethics Committee of Okasha Institute of Psychiatry, Ain Shams University. The reference number is not available as at the time of conducting this study, the ethical approval was only a necessity at the departmental level without any other prerequisites from the university.

\section{Consent for publication}

Not applicable

\section{Competing interests}

The authors declare that they have no competing interests.

\section{Author details}

'Okasha's Institute of Psychiatry, The WHO Collaborating Center for Mental Health Research \& Training, Department of Neuropsychiatry, Ain Shams University, Abbasseyia, Ramses Street Extension, Dair Al-Malak, P.O. Box: 11657, Cairo, Egypt. ${ }^{2}$ Community Medicine \& Public Health, Faculty of Medicine, Tanta University, Tanta, Egypt. ${ }^{3}$ El Abassia Mental Hospital, Cairo, Egypt.

Received: 6 October 2020 Accepted: 9 November 2020

Published online: 25 November 2020

\section{References}

1. Lawler M, Nixon E (2011) Body dissatisfaction among adolescent boys and girls: the effects of body mass, peer appearance culture and internalization of appearance ideals. J Youth Adolesc 40(1):59-71

2. Bun CJ, Schwiebbe L, Schütz FN, Bijlsma-Schlösser JF, Hirasing RA (2012) Negative body image and weight loss behavior in Dutch school children. Eur J Public Health 22(1):130-133

3. Davison TE, McCabe MP (2006) Adolescent body image and psychosocial functioning. J Soc Psychol 146(1):15-30

4. Lee J, Lee $Y$ (2016) The association of body image distortion with weight control behaviors, diet behaviors, physical activity, sadness, and suicidal ideation among Korean high school students: a cross-sectional study. BCM Public Health 16:39
5. Rodgers RF, Paxton SJ, McLean SA (2014) A biopsychosocial model of body image concerns and disordered eating in early adolescents' girls. J Youth Adolesc 43(5):814-823

6. Le Grange D, Crosby R, Rathouz P, Leventhal B (2007) A randomized controlled comparison of family-based treatment and supportive psychotherapy for adolescent bulimia nervosa. Archives of General Psychiatry 64:1049-1056

7. Bryant-Waugh R, Lask B (2013) Overview of eating disorders in childhood and adolescence. In: Bryant-Waugh R, Lask B (eds) eating disorders in childhood and adolescence. Routledge, New York, pp 33-49

8. Nasser M (1997) The sociocultural model of eating pathology. Culture and weight consciousness. Routledge, London

9. Ghannam F (1997) Fertile, plump and strong: the social construction of female body in low-income Cairo. Monographs in Reproductive Health no.3. Population Council Regional Office for West Asia and North Africa, Cairo

10. Al-Subaie AS (2000) Some correlates of dieting behavior in Saudi schoolgirls. Int J Eat Disord 28:242-246

11. Levine M (1987) How schools can combat student eating disorders: anorexia nervosa and bulimia. National Education Association, Washington, DC

12. Neumark-Sztainer D, Story M, Coller T (1999) Perceptions of secondary school staff toward the implementation of school-based activities to prevent weight-related disorders: a needs assessment. Am J Health Promot 13:153-156

13. Yager J, Andersen AE (2005) Clinical practice. Anorexia nervosa. N Engl J Med. 353(14):1481-1488

14. Stang J, Story M, Kalina B (1997) School-based weight management services: perceptions and practices of school nurses and administrators. Am J Health Promot 11:183-185

15. Garner DM, Garfinkel PE (1979) The Eating Attitudes Test: an index of the symptoms of anorexia nervosa. Psychol Med 9:273-279

16. Button EJ, Whitehouse A (1981) Subclinical anorexia nervosa. Psychol Med 9: 273-279

17. Nasser M (1994) The psychometric properties of the Eating Attitude Test in a non-Western population. Soc Psychiatry Psychiatr Epidemiol. 29(2):88-94

18. El Missiry A, Sorour A, Sadek A, Fahy T, AbdelMawgoud M, Asaad T (2004) Homicide and psychiatric illness: An Egyptian study (MD Thesis). Faculty of Medicine, Ain Shams University, Cairo

19. Mazzeo SE (1999) Modification of an existing measure of body image preoccupation and its relationship to disordered eating in female college students. J Couns Psychol 46(1):42-50. https://doi.org/10.1037/0022-0167.46.1.42

20. ElDesouky MM (2004) Body Shape Questionnaire- Revised-10- Arabic version. EINahda EIMasria Library, Cairo

21. Cooper PJ, Taylor MJ, Cooper Z, Fairbum CG (1987) The development and validation of the Body Shape Questionnaire. Int J Eat Disord 6(4):485-494

22. El Dereni H, Salama M, Kamel A (1982) Self-esteem Scale. Dar El Fikr El Arabi, Cairo

23. Gowers SG, Bryant-Waugh R (2004) Management of child and adolescent eating disorders: the current evidence base and future directions. J Child Psychol Psychiatry 45:63-83

24. Abdulrahman OM, Mariam AM, Reema T, Osama AA, Essa YH, Faiza K, Mofida MB, Sabri S, Ismail H, Zahra D, Ch M (2012) Prevalence of overweight and obesity among adolescents in seven Arab countries: a cross-cultural study. J Obes 2012:981390, 5 pages. https://doi.org/10.1155/2012/981390

25. Ogden, CLet al (2004) Mean body weight, height, and body mass index, United States 1960-2002 advance data from vital and health statistics, Number 347

26. Janssen I, Heymsfield S, Wang Z, Ross R (2000) Skeletal muscle mass and distribution in 468 men and women aged 18-88 yr. J Appl Physiol 89(1):81-88

27. Vella CA, Kravitz L, Kravitz MS (2002) Gender differences in fat metabolism. IDEA Health and fitness source 20(10):36-46

28. Olweus D, Mattsson A, Schalling D, Löw H (1988) Circulating testosterone levels and aggression in adolescent males: a causal analysis. Psychosom Med 50(3):261-272

29. Ackard DM, Fulkerson JA, Neumark-Sztainer D (2007) Prevalence and utility of DSM-IV eating disorder diagnostic criteria among youth. Int J Eat Disord 40(5):409-417

30. Anderson CB, Bulik CM (2004) Gender differences in compensatory behaviors, weight and shape salience, and drive for thinness. Eat Behav. 5:1-11

31. Culbert KM, Racine SE, Klump KL (2011) The influence of gender and puberty on the heritability of disordered eating symptoms. Curr Top Behav Neurosci. 6:177-185 
32. Lewinsohn PM, Seeley JR, Moerk KC, Striegel-Moore RH (2002) Gender differences in eating disorder symptoms in young adults. Int J Eat Disord. 32:426-440

33. Mintz LB, O'Halloran MS (2000) The Eating Attitudes Test: validation with DSM-IV eating disorder criteria. J Pers Assess 74:489-504

34. Okasha A, Mahmoud S (2009) Prevalence of eating disorders among female students, MD thesis, Ain Shams University, Cairo, Egypt. [Quoted from: Okasha A. 2009: Would the use of dimensions instead of categories remove problems related to subthreshold disorders?]. Eur Arch Psychiatry Clin Neurosci 1998 259(Suppl 2):S12933

35. Fawzi MM, Haitham M, Hashim AA, Nelly RA (2010) Prevalence of eating disorders in a sample of rural and urban secondary schoolgirls in Sharkia, Egypt. Curr Psychiatry 17:1-12

36. Eapen V, Abdel Azim M, Salem BO (2006) Disordered eating attitudes and symptomatology among adolescent girls in the United Arab Emirates. Eat Behav 7:53-60

37. Sepulveda AR, Carrobles JA, Gandarillas AM (2008) Gender, school and academic year differences among Spanish university students at high-risk for developing an eating disorder: an epidemiologic study. BMC Public Health. 8:102

38. Roberta S, Sylvia F, Maria P, Helen H, Silvia P (2017) Overweight and body image perception in adolescents with triage of eating disorders. Scientific World Journal 2017:8257329

39. Tamara YM, Hayder AA, Rima HM, Musa AJ (2010) Eating disturbances among adolescent schoolgirls in Jordan. Appetite 54:196-201

40. Swanson SA, Crow SJ, Le Grange D, Swendsen J, Merikangas KR (2011) Prevalence and correlates of eating disorders in adolescents: results from the national comorbidity survey replication adolescent supplement. Arch Gen Psychiatry 68:714-723

41. Hoek H, Hoeken D (2003) Review of prevalence and incidence of eating disorders. Int J Eat Disord. 34:383-396

42. Bulik CM, Sullivan PF, Tozzi F, Furberg H, Lichtenstein P, Pedersen NL (2006) Prevalence, heritability, and prospective risk factors for anorexia nervosa. Arch Gen Psychiatry 63(3):305-313. https://doi.org/10.1001/archpsyc.63.3.305

43. Bijl RV, Ravelli A, van Zessen G (1998) Prevalence of psychiatric disorder in the general population: results of the Netherlands Mental Health Survey and Incidence Study (NEMESIS). Soc Psychiatry Psychiatr Epidemiol 33:587-595

44. Preti A, de Girolamo G, Vilagut $G$ et al (2009) the epidemiology of eating disorders in six European countries: results of the ESEMeD-WMH project. J. Psychiatr. Res. 43:1125-1132

45. Smink FRE, van Hoeken D, Oldehinkel AJ, Hoek HW (2014) Prevalence and severity of DSM- 5 eating disorders in a community cohort of adolescents. Int J Eat Disord 47:610-619

46. Wassenaar D, Grange DL, Winship J, Lachenicht L (2000) The prevalence of eating disorder pathology in a cross-ethnic population of female students in South Africa. European Eating Disorders Review 8(3):225-236

47. Favaro A, Ferrara S, Santonastaso P (2003) The spectrum of eating disorders in young women: a prevalence study in a general population sample. Psychosom. Med. 65:701-708

48. Keski-Rahkonen A, Hoek HW, Linna MS et al (2008) Incidence and outcomes of bulimia nervosa: a nationwide population-based study. Psychol. Med. 8:1-9

49. Kohn M, Golden NH (2001) Eating disorders in children and adolescents: Epidemiology, diagnosis and treatment. Pediatr Drugs 3(2):91-99

50. Paulson LR, Rutledfe PC (2013) Effects of perfectionism and exercise and disordered eating in college students. Eat Behav:15

51. Hilbert A, Braehler E, Haeuser W, Zenger M (2014) Weight bias internalization, core self-evaluation, and health in overweight and obese persons. Obesity (Silver Spring) 22:79-85

52. Mäkinen M, Puuko-Viertomies LR, Lindberg N, Siimes MA, Aalberg V (2012) Body dissatisfaction and body mass in girls and boys transitioning from early to mid-adolescence: additional role of self-esteem and eating habits. BMC Psychiatry 12:1-9

53. Stice E, Ng J, Shaw H (2010) Risk factors and prodromal eating pathology. J Child Psychol Psychiatry 51(4):518-525

54. Fairburn CG, Harrison PJ (2003) Eating disorders. Lancet 361(9355):407-416

\section{Publisher's Note}

Springer Nature remains neutral with regard to jurisdictional claims in published maps and institutional affiliations.

\section{Submit your manuscript to a SpringerOpen ${ }^{\circ}$ journal and benefit from:}

- Convenient online submission

- Rigorous peer review

- Open access: articles freely available online

- High visibility within the field

- Retaining the copyright to your article

Submit your next manuscript at $\boldsymbol{\nabla}$ springeropen.com 